Nunt. Antiquus, Belo Horizonte, v. 14, n. 2, p. 13-32, 2018

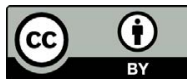

\title{
O banho de Diomedes e Odisseu no fim do canto X da Ilíada (572-577)
}

\section{Diomedes and Odysseus'Bath at the End of Iliad's Book X (572-577)}

Teodoro Rennó Assunção

Universidade Federal de Minas Gerais (UFMG), Belo Horizonte, Minas Gerais / Brasil teorenno@gmail.com

Resumo: Este artigo pretende comentar com algum cuidado a cena do banho de Diomedes e Odisseu no fim do canto X da Ilíada (572-577), cena de algum modo atípica (ainda que se conforme basicamente ao padrão das "cenas típicas" de banho da Odisseia) em um canto também atípico (por descrever uma missão noturna de espionagem desta dupla de aqueus no acampamento troiano), por ser a única cena de banho de heróis mortais realizada na Ilíada, e, justamente por isso, tentando contrastála com a breve cena de banho do deus Ares e com as outras cenas de banho de heróis apenas sugeridas, mas não efetivadas neste poema.

Palavras-chave: banho; Diomedes; Odisseu; cena típica; canto X; Ilíada.

Abstract: The aim of this article is to comment carefully on the scene of Diomedes and Odysseus' bath at the end of Iliad's Book X (572-577). Such a scene is somehow atypical, even though it basically conforms to the pattern of Odyssey's bathing "typescenes". Besides that point, this scene is located in a book that is also atypical in the Iliad because it describes these two Achaeans' nocturnal mission of spying on the Trojan camp. The atypicality of this episode is due to the fact that it portrays the only mortal heroes' bathing scene that happens in the Iliad. Therefore, this article tries to contrast the aforementioned scene with the brief scene of god Ares' bath and with other mortal heroes' bathing scenes which were only suggested, yet did not happen in this poem.

Keywords: bath; Diomedes; Odysseus; type-scene; book X; Iliad. 
Apesar de quase poder passar despercebida na Ilíada - por sua pouca importância para a intriga principal da cólera (mênis) de Aquiles e a decisão final da guerra de Troia (apenas o desfecho positivo de uma missão noturna de espionagem, com uma vitória pontual da dupla de espiões aqueus que mata o espião troiano e treze aliados trácios que dormiam, além de roubarem os dois excepcionais cavalos de seu rei Reso) - a cena do banho de Diomedes e Odisseu no fim do canto X da Ilíada (572-577) é uma curiosidade aparentemente estranha neste canto também algo estranho (pois único em seu modo não convencional de fazer a guerra) ${ }^{1}$ pois ela é, no presente (e mesmo no passado) narrativo da Ilíada, a única cena de banho de heróis mortais vivos (pois há uma brevíssima do deus Ares, cf. Il. V, 905), realizada e não apenas pensada como possibilidade (pois ao menos três são imaginadas assim) neste poema, ou seja: um hápax legómenon ("algo dito uma única vez") narrativo, com também a única ocorrência na Ilíada do termo asáminthos ("banheira") $)^{2}$ e uma combinação única de um banho prévio no mar e de

\footnotetext{
${ }^{1}$ Não é minha intenção aqui retomar toda a enorme discussão erudita sobre a pretensa estranheza e não autenticidade do canto X da Ilíada, que pode se confundir de alguma maneira com a ainda mais difícil e complexa questão da autoria da Ilíada e da Odisseia (ou "questão homérica"), mas irei apenas definir brevissimamente minha posição como sendo, em princípio, favorável à ideia de uma longa tradição oral homérica (isto é, de várias gerações de cantores recriadores destes dois poemas e não de um ou dois poetas individuais com o nome próprio de "Homero") de composição através não somente de "fórmulas" no sentido proposto por Milman Parry (de "um grupo de palavras, regularmente utilizado nas mesmas condições métricas, para exprimir uma dada ideia essencial", apud NAGY, 1979, p. 1), mas também de "temas" ou "unidades narrativas que se repetem" (ainda que não exatamente palavra a palavra, como no caso das fórmulas com que eles são construídos e aos quais elas servem) tais como propostos primeiramente por Albert Lord (cf. LORD, 1951, p. 73), estando, portanto, basicamente de acordo com as posições de Casey Dué e Mary Ebbott no seu grande livro sobre o canto X da Ilíada (Iliad 10 and the Poetics of Ambush [2010]), quando consideram que este faz parte integralmente deste poema e desta tradição, ainda que tematicamente ele possa parecer minoritário ou excepcional na Ilíada e mais próximo da Odisseia (ver, para tanto, todo o capítulo 1, "Interpreting Iliad 10", [DUÉ; EBBOTT, 2010, p. 3-29]).

${ }^{2}$ Steve Reece, estudando este termo no breve artigo "The Homeric A A $\alpha \dot{\mu} \mu v \theta$ oc: Stirring the Waters of the Mycenaean Bath" (2002), lembra não só da existência atestada de "banheiras" no chamado "palácio de Nestor" em Pilos, mas também da descoberta de
} 
um banho de banheira (com unção de óleo) que antecede uma refeição com uma libação à deusa Atena.

Vejamos, então, de um modo um pouco mais alargado, esta cena de banho - nosso objeto primeiro - em uma tradução (ou primeira interpretação) que visa apenas a alguma precisão semântica (incluindo a maneira sintática), mas não a uma qualquer correspondência rítmica com o hexâmetro dactílico:

E na popa da nau os despojos sangrentos de Dólon pôs Odisseu, pra que preparassem a oferenda pra Atena.

E eles próprios o suor abundante lavaram, no mar entrando, em torno das pernas, pescoço e coxas. Mas depois que a onda do mar seu suor abundante lavou da pele e foram refrescados no caro coração, nas banheiras bem-polidas entrando, se banharam. E os dois, tendo se banhado e ungido à larga com óleo, para o jantar se assentaram, e da ânfora cheia retirando o vinho prazer-de-mel, a Atena libaram.

(Iliada X, 570-579) ${ }^{3}$

uma espécie de "selo" em metal em Cnossos, tendo em um dos lados a figura de um cervo, e no outro duas inscrições em Linear B que se leem como: ke-ni-qa (khérniba, "bacia pra lavar as mãos") e $a$-sa-mi-to (asáminthos, "banheira”), termos encontráveis em Homero, mas já presentes na civilização micênica do segundo milênio a.C., ainda que asáminthos não fosse mais na primeira metade do primeiro milênio a.C. o termo mais comum para designar uma "banheira" (ver, p. ex., púelos, baláneion ou skáphê), mas que teria se conservado (como um "fóssil") na tradição épica hexamétrica por meio do seu uso em fórmulas preenchendo o primeiro hemistíquio do verso. E, quanto à etimologia, S. Reece ainda crê na possibilidade de um empréstimo a partir do acádio namsitu ("bacia para lavagem" ou "banheira"), tal como proposto por Szemerényi (REECE, 2002). Aproveito esta nota também para informar que na transliteração do grego adotei a prática de sublinhar os " $e$ "s e " $o$ "s longos (étas e ômegas) para diferenciálos dos " $e$ "s e " $o$ "s breves (épsilons e ómicrons).

${ }^{3}$ Adoto para todas as passagens citadas da Ilíada (sempre aqui em traduções minhas) o texto grego da edição de Thomas W. Allen e David B. Monro (Homeri Opera: Ilias, 1989). Foram cotejadas as edições do texto grego de Helmut van Thiel (Homeri Ilias, 1996) e de Martin L. West (Homeri Ilias, volumen prius; volumen alterum, 1998; 2000). Dado o critério semântico-sintático (e não métrico ou rítmico) das minhas traduções, foram consultadas para cotejo as traduções da Ilíada para o português de Carlos Alberto 
Ainda que composta com elementos de uma cena homérica típica de banho (em que certos elementos básicos aparecem numa certa ordem: banho, unção de óleo e o vestir roupas novas $)^{4}$ tal como encontrada com alguma frequência na Odisseia (são oito ocorrências, das quais duas contêm o mesmo verso 576 de Ilíada X: Odisseia IV, 48 e XVII, 87), fazendo parte, portanto, de um repertório épico tradicional de unidades narrativas (assim como também as cenas típicas de banho ou lavagem dos cadáveres de Pátroclo e de Heitor, que seguem um padrão análogo, o confirmam por sua importância no último terço do poema), esta cena é única na Ilíada (tornando difícil, na ausência de uma série, considerá-la típica aí) e poderia levar à questão de por que não ocorrem outras cenas de banho de heróis mortais vivos neste poema ou a de por que apenas nela uma "banheira" (asáminthos) é mencionada (e, o que poderia ser considerado mais desconcertante, no acampamento dos aqueus e não no palácio de Príamo, por exemplo).

Mas, antes de comentar esta cena (pensando-a também no quadro único do canto X), e deixando de lado (para uma outra ocasião) as importantes cenas de banho dos cadáveres de Pátroclo e de Heitor (assim como a do de Sárpedon, que é, porém, diferenciada), ${ }^{5}$ eu gostaria de citar

Nunes (2011) e de Frederico Lourenço (2005). Os itálicos, usados para destacar (em todas as passagens citadas) as cenas mais estritas de banho, são sempre meus.

${ }^{4}$ Ver para a definição de "cena típica" homérica e, em particular, a do banho, o capítulo 10, "Bad", na obra pioneira Die typischen Scenen bei Homer de Walter Arend, que a define assim (nesta ordem sucessiva): "Lavar, ungir e colocar vestes limpas" ("Waschen, Salben und Anlegen reiner Kleidung"; AREND, 1933, p. 124). Para um estudo das "cenas típicas" (ou "temas", segundo o conceito de Albert Lord) de banho na Odisseia, ver também o subcapítulo "The Bath" no capítulo 7 ("Thematic Structure in the Odyssey") de Traditional Oral Epic de John Miles Foley (1990, p. 248-257). Para uma definição de "tema", com suas possíveis expansões, abreviações e conexões com outros temas, ver ainda o capítulo 4 ("The Theme") do fundamental The Singer of Tales de Albert B. Lord (2000, p. 68-98). E para uma definição da cena típica do banho no quadro ritual maior da hospitalidade, ver a seção 3.1.2 ("Bathing") do subcapítulo 3.1 ("Hospitality in General") do artigo "Homer and the Oral Tradition: The Type-Scene" de Mark W. Edwards (1992, p. 306).

${ }^{5}$ Ver, para os banhos dos cadáveres na Ilíada, o artigo focado neles "The Poetics of Bath in the Iliad" de Jonas Grethlein (2007). 
e comentar bem sucintamente as outras cenas de banho, pensadas como possibilidades, mas não efetivadas, de heróis mortais vivos na Ilíada, assim como a brevíssima do deus Ares, para não só percebermos o seu outro padrão, mas também para eventualmente delas extrairmos algumas conexões básicas, que poderiam ajudar a compreender melhor esta cena única de banho (e sua razão de sê-lo) efetivada no fim do canto X.

Comecemos, então, com um mesmo critério de tradução, pela cena ultraconcisa (um verso apenas: V, 905) do banho do deus Ares:

E a este, Peéon, sobre-aspergindo drogas destrói-dores, curou; pois de modo nenhum fora feito como um mortal. $[\ldots]$,

assim, então, rapidamente ele curou o impetuoso Ares. E a este Juventude banhou, e graciosas vestes vestiu nele; e junto de Zeus Cronida se assentou, brilhando de glória.

(Iliada V, 900-901; 904-906)

Se, do ponto de vista da cena típica (tal como definida em seus três elementos mínimos por Walter Arend [1933, p. 124]), este banho divino brevíssimo faz a economia da unção com óleo, ele se dá em um contexto não só de um retorno de Ares (ferido por Diomedes com a ajuda de Atena) ao palácio olímpico, mas também de uma rápida e fácil cura (como é própria ao corpo de deuses imortais) que, juntamente com o banho (dado por uma "serva" divina cujo nome não é gratuito), o rejuvenesce e explicita a sua intensidade de vida. Chama a atenção também o fato de que, logo depois do banho, Ares se assentou junto do anfitrião e senhor do palácio (Zeus), mas sem que se siga, como é comum neste tipo de cena, um banquete.

Vejamos agora, então, a primeira cena de um banho imaginado (mas não realizado ou descrito) de um herói vivo coincidentemente ferido, o médico-guerreiro Macáon, levado por Nestor de volta ao acampamento aqueu (e à sua barraca), onde, após um coquetel de vinho de Pramno, queijo de cabra ralado e cevada polvilhada, preparado por Hecamede, ele não só sacia sua sede, mas parece se restabelecer para ouvir e contar histórias com Nestor (cf. Ilíada XI, 638-643). Mas quando Nestor propõe a ele o repouso com a fruição do vinho e um banho para lavar a sujeira 
do sangue, a situação já é de pressão dos troianos junto ao acampamento aqueu, o que poderia inclusive anular a salvação de sua vida que não só o retorno, mas também a bebida e o banho poderiam estar sinalizando:

"Maior então junto às naus [é] o grito de vigorosos jovens.

Que tu mesmo agora bebas sentado o vinho flamejante, até que belas-tranças Hecamede a água quente de banho esquente e lave for os coágulos sanguinolentos; Mas eu, chegando ao miradouro, rápido saberei."

(Ilíada XIV, 4-8)

Chama a atenção aqui não só o fato de o beber o vinho anteceder o banho (em uma inversão da relação entre a cena do banho, como preparação, e a do banquete que tradicionalmente a sucede), como também, no que é a preparação para o banho com o aquecimento da água (algo que, como expansão possível, não faz parte do núcleo duro triplo da cena típica de banho), a menção apenas do elemento da lavagem da sujeira do sangue expelido da ferida (no ombro direito por uma flecha de Alexandre, cf. Ilíada XI, 505-507), em que a água quente poderia ter uma função purificatória e terapêutica, mas nada sendo dito sobre a unção com óleo de oliva e nem sobre o vestir novas roupas. Ainda que seja possível que este banho tivesse "acontecido", a Ilíada (nossa única e ficcional fonte) nada mais diz sobre ele.

Vejamos o exemplo seguinte de banho imaginado (e não descrito), em que podemos ter a certeza de que ele não "aconteceu", pois o herói que é suposto estar vivo - e para quem o banho começa a ser preparado (por meio da ordem de Andrômaca, sua mulher) - simplesmente (ou trágico-ironicamente) já está morto: Heitor.

E ordenou às servas de-belas-tranças pela casa colocar no fogo uma grande trípode, pra que houvesse água quente de banho pra Heitor ao voltar do combate; tola, pois não percebeu que, bem longe da água de banho, pelas mãos de Aquiles o subjugara a olhos-de-coruja Atena.

(Ilíada XXII, 442-446) 
Obviamente aqui também apenas uma ordem para o aquecimento da água é descrita, e sem a menção da sua função quanto a um possível sangue coagulado ou poeira (a lavagem não sendo nomeada e muito menos o óleo para unção ou as roupas novas para vestir), mas a menção de "uma grande trípode" a ser colocada no fogo (instrumento tradicional para o aquecimento da água) indica o quanto o grande palácio de Príamo ou os aposentos de Heitor (como os da Odisseia) estariam aparelhados para preparar um bom banho quente (ainda que jamais aí uma "banheira" seja mencionada). No entanto, a breve descrição é suficiente para marcar o quanto em Homero um banho pressupõe para o que é banhado ou se banha o estar vivo e em segurança, e, portanto, o quanto está "bem longe da água de banho" quem foi morto em combate como Heitor (a não ser que pensássemos que, em um deslocamento, o que ou quem será banhado, ungido com óleo e vestido com roupas novas será apenas o seu cadáver, mas, ainda uma vez ironicamente, não por ordem de Andrômaca, mas pela de Aquiles, o seu matador, cf. Ilíada XXIV, 582-588). ${ }^{6}$

Vejamos, enfim, uma última e abortada tentativa de preparação de um banho quente (por ordem de alguns reis que o acompanham), desta vez para Aquiles que, em seu obstinado luto por Pátroclo, se recusa a se banhar, mesmo que esteja sujo de sangue, até o fim do poema (ainda que acabe concedendo voltar a comer e a dormir, quebrando um pouco a sua identificação com o morto):

\footnotetext{
${ }^{6}$ Assim, portanto, não haveria necessariamente uma incompatibilidade total entre o mundo da guerra (desde que o guerreiro consiga temporariamente sobreviver) e um ato purificatório como o do banho, apesar de o banho evocar em princípio uma situação de relativa segurança e conforto, que parece mais própria ao mundo da paz, como bem o percebeu Simone Weil, no conhecido ensaio "A Ilíada ou o poema da força", ao comentar (depois de citar) exatamente esta cena de inútil preparação de um banho quente para Heitor: "O infeliz, é claro, estava longe dos banhos quentes. Não era o único. Quase toda a Ilíada se passa longe dos banhos quentes. Quase toda a vida humana se passou longe dos banhos quentes" (WEIL, 1996, p. 380). Ver também as observações de Jonas Grethlein sobre este banho abortado no artigo "The Poetics of Bath in the Iliad" (2007, p. 26-30).
} 
E estes, quando então chegaram à barraca de Agamêmnon, de imediato ordenaram aos arautos de-clara-voz colocar no fogo uma grande trípode, pra convencerem o Pelida a lavar fora os coágulos sanguinolentos.

Mas este recusou firmemente e jurou um juramento: "Não, por Zeus, que é o mais alto e o melhor dos deuses, não é lícito a água de banho chegar perto da cabeça, antes de pôr Pátroclo no fogo e lhe fazer um túmulo [...]"

(Ilíada XXIII, 38-45)

Também aqui o que temos é apenas uma ordem para o aquecimento da água (com uma fórmula já usada que menciona "uma grande trípode", portanto um utensílio presente também no acampamento dos aqueus), e com a menção de sua função purificatória dos "coágulos sanguinolentos" (com uma fórmula também já usada, ainda que aqui não possamos dizer que os coágulos venham de uma ferida do próprio Aquiles), mas Aquiles diz não se sentir autorizado a tomar este banho, enquanto os ritos fúnebres para Pátroclo não forem efetivados, deixando claro o quanto o luto, em sua mimetização do estado do morto, afasta o enlutado de ações rituais que supõem uma básica integração à economia da vida, como o banho e o banquete, que, por sinal, acompanha na imediata sequência (cf. Ilíada XXIII, 55-57), em uma conexão tradicional, este banho projetado e abortado por Aquiles.

Voltemos, enfim, depois desta rápida verificação destas outras parciais e negativas ocorrências de banho na Ilíada (além da brevíssima e positiva do deus Ares), geralmente em conexão com a morte (ou o luto) ou uma situação de não segurança, à nossa única cena efetiva de banho de heróis vivos na Ilíada, a de Diomedes e Odisseu no fim do canto $\mathrm{X}$, para tentar comentar sucintamente como ela está construída internamente, e também como ela se conecta com o canto (também único) que ela conclui: 
E eles próprios o suor abundante lavaram, no mar entrando, em torno das pernas, pescoço e coxas. Mas depois que a onda do mar seu suor abundante lavou da pele e foram refrescados no caro coração, nas banheiras bem-polidas entrando, se banharam. E os dois, tendo se banhado e ungido à larga com óleo, para o jantar se assentaram, e da ânfora cheia retirando o vinho prazer-de-mel, a Atena libaram.

(Ilíada X, 572-579)

O que primeiro e estruturalmente chama a atenção, neste único banho realizado na Ilíada, é o fato (único também) de que ele é um banho duplo: primeiro um banho no mar (quatro versos) para a lavagem do "suor abundante" (hidrô pollòn) (e o "refrescar" ou "retomar fôlego": anépsykhthen "no caro coração") e depois um banho em "banheiras bem-polidas" (dois versos), com a menção da unção com óleo, mas sem nenhuma menção das roupas vestidas, e a transição tradicional para um cena de banquete (e libação) por meio do ato de se assentarem. No que são os dois breves versos que descrevem o banho de banheira (o primeiro dos quais ocorre também em Odisseia IV, 48 - para a dupla Telêmaco e Pisístrato -, e XVII, 87 - para a dupla Telêmaco e Teoclímeno -, enquanto o segundo é quase o mesmo, apenas com a troca do plural feminino por um dual aqui, que o verso 96 de Odisseia VI) não há nenhuma menção sobre o aquecimento ou a temperatura da água (apesar de ser madrugada) ${ }^{7}$ ou sobre um eventual efeito terapêutico desta, mas a função purificatória (mais do que higiênica) se justifica não apenas por ser ele uma preparação tradicional para o jantar (deípnoi $)$, mas por conter este uma libação ritual (leîbon) de agradecimento a Atena.

\footnotetext{
${ }^{7}$ Tanto Bryan Hainsworth quanto Casey Dué e Mary Ebbott parecem supor em seus comentários que o banho possivelmente é quente, apesar de nada sobre o aquecimento da água ser explicitado: "[...] eles desfrutam o prazer do banho (quente) como se estivessem se preparando para um banquete. [...] O relato do banho e refeição é quase absurdamente lacônico e omite o aquecimento da água [...]" (HAINSWORTH, 1993, p. 209, tradução minha). "O último [i.e. um banho numa banheira] é talvez um banho quente, mesmo se a linguagem vista em outros lugares na poesia homérica a respeito do aquecimento da água não está incluída aqui”' (DUÉ; EBBOTT, 2010, p. 378, tradução minha).
} 
Esta função poderia, por exemplo, ser conectada na Ilíada à lavagem de uma taça (inclusive com enxofre) e das mãos por Aquiles, antes que ele faça uma libação e uma súplica a Zeus, pedindo o bom sucesso no combate (e o retorno às suas naus) de Pátroclo e dos Mirmidões (cf. Ilíada XVI, 225-233), ou à lavagem das mãos que precede a libação e súplica a Zeus por Príamo (cf. Ilíada XXIV, 302-307), para que seja bem-sucedido em sua ida à tenda de Aquiles buscar o cadáver de Heitor (cf. Ilíada XXIV, 308-309), assim como também à recusa por Heitor, sujo de sangue e poeira (em seu breve retorno do campo de batalha à cidade de Troia), de fazer uma libação de vinho a Zeus, como a sugerida por sua mãe (cf. Ilíada VI, 266-268). ${ }^{8}$ Ou seja: é o contato ritual com a esfera divina o que demandaria um estado de pureza ou o estar purificado, esclarecendo a dimensão religiosa do banho (ou a da lavagem das mãos). ${ }^{9}$

\footnotetext{
${ }^{8}$ Analogamente, duas cenas de prece a uma divindade na Odisseia (a de Telêmaco para Atena, que ele ainda não reconheceu, em Odisseia II, 261; e a de Odisseu para todos os deuses olímpicos, em Odisseia XII, 336) são antecedidas pela lavagem das mãos na água do mar. E semelhantemente os dois banhos (ou "banhos de gato"?) de Penélope, descritos por um único e mesmo verso (Odisseia IV, 759 = XVII, 58; precedido por ligeira variação dele mesmo em Odisseia IV, $750=$ XVII, 48) precedem uma prece ou súplica a uma divindade: no fim do canto IV para Atena, e no começo do canto XVII para todos os deuses olímpicos.

${ }^{9}$ Como observa com razão Jean-Pierre Vernant (no artigo "Le pur et l'impur"): “A limpeza física ultrapassa [...] o domínio do corpo. A mancha que o suja avilta o indivíduo e o torna feio. Proíbe-o também de entrar em contato com os deuses: o homem deve se lavar antes dos atos de culto. [...] Não se apresentaria a limpeza física [em Homero], logo de cara, como um valor religioso?" (VERNANT, 1974, p. 122, tradução minha). Ou ainda: “A sujeira 'física' no sentido de Homero e Hesíodo só se compreende [...] no quadro de um sistema religioso de pensamento. Uma 'sujidade' aparece como um contato contrário a uma certa ordem do mundo pelo fato de que ele estabelece uma comunicação entre realidades que devem permanecer bem distintas" (VERNANT, 1974, p. 131, tradução minha). Esta dimensão religiosa do banho (analogamente à da lavagem das mãos) estaria, por outro lado, conectada também à dimensão ritual da refeição (mesmo que o elemento do sacrifício não seja explicitado em sua preparação), tal como o sugere R. Ginouvès (em Balaneutiké: Recherches sur le bain dans l'Antiquité grecque): “Também pode-se admitir que este gesto correspondia, ao menos em parte, à 'purificação necessária antes de realizar um ato religioso'. Com efeito, a refeição parece ser, nesta sociedade, um ato com valor religioso, tanto em circunstâncias ordinárias quanto em situações nas quais ela é a sequência de um sacrifício solene" (GINOUVÈS, 1962, p. 152, tradução minha).
} 
$\mathrm{Na}$ conclusão do canto $\mathrm{X}$, no entanto, a divindade não é Zeus, mas Atena, para quem no início da cena da chegada ao acampamento (com o efeito de uma microcomposição em anel) Odisseu colocou na popa da nau "os despojos sangrentos de Dólon" (énara Dólonos, Ilíada $X, 570$ ) enquanto "uma oferenda sacrificial" (hiròn, Ilíada X, 571) da dupla. O que também está em perfeita consonância com todo o cuidado religioso dos dois para com esta divindade guerreira astuciosa, ao longo deste canto, desde a escolha de Odisseu como companheiro por Diomedes (cf. Ilíada X, 245) e as duas orações ou súplicas a ela (a de Odisseu e depois a de Diomedes, cf. Ilíada X, 277-294), depois que ela se manifesta sonoramente, porque é noite, como uma garça (cf. Ilíada X, 274-276).

Mas o banho inicial no mar (assim como o banho duplo) merece, por seu insólito homérico (na Odisseia o banho no rio, justamente para tirar a salsugem do mar, e depois o de banheira de Odisseu na Feácia estão separados espacial e temporalmente), uma tentativa de comentário e interpretação. Curiosamente, no canto I da Ilíada, em um momento que precede a tentativa por Agamêmnon de aplacar a cólera de Apolo e a peste enviada ao acampamento aqueu com a devolução de Criseida e uma hecatombe a este deus em Crisa, Agamêmnon propõe ao seu exército em Troia uma purificação (com o uso de um verbo, apolymainesthai, menos genérico do que "banhar" ou "lavar", loéo ou nízo) no mar e também a realização de uma hecatombe ao deus:

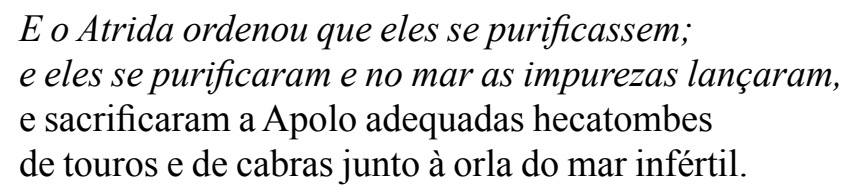

(llíada I, 313-316)

Ora, ainda que a sujeira retirada no banho de mar por Diomedes e Odisseu não inclua o sangue e seja dita apenas um "suor abundante" (que recobriria a "pele"), justificável por toda a ação noturna arriscada e de grande esforço físico realizada pela dupla (com também o deitar junto a cadáveres, o correr e o cavalgar carregando despojos), não podemos nos esquecer com facilidade de que os dois - ou mais precisamente Diomedes - não só decapitaram o espião troiano Dólon (depois de 
colher informações dele), mas também mataram treze guerreiros trácios que estavam dormindo, ${ }^{10} \mathrm{em}$ um ataque surpresa muito pouco leal, mas condizente com uma expedição noturna de espionagem e guerrilha. Seria possível lembrar que após o massacre dos 108 pretendentes na Odisseia, no que foi também um ataque surpresa (ou "emboscada", lókhos), Odisseu não somente purifica o salão do palácio com enxofre e fogo (cf. Odisseia XXII, 491-494), como também ordena que todos que participaram dele (Telêmaco, Eumeu e Filécio, além dele mesmo) tomem um banho purificatório que deve também preceder uma festa de casamento fingido, e, no caso dele mesmo, o seu encontro final e ida para o leito com Penélope (cf. Odisseia XXIII, 130-163).

Esta última conexão com o ataque surpresa aos pretendentes na Odisseia talvez permita também pensar a relação entre este banho único na Ilíada e o canto X, que - como bem demonstraram Casey Dué e Mary Ebbott no livro Iliad 10 and the Poetics of Ambush (2010, p. 31-87), que aqui nos serve de base - também é único e insólito no presente narrativo da Ilíada (mas não nas histórias de razias de gado, como a contada por Nestor no canto XI), por ser uma história de uma missão de espionagem noturna, cuja lógica e organização (que os autores definem como sendo a de uma "emboscada" ou lókhos) é completamente diferenciada da do combate aberto em pleno dia, que caracteriza a imensa maioria dos combates neste poema de guerra, assim como dos modos de comportamento guerreiro "leal" a ele associados. Ela é, por isso, mais próxima, no seu privilegiar a mêtis ("astúcia"), o disfarce e o engano (e não a força física ou a simples coragem), de vários episódios

\footnotetext{
${ }^{10}$ Annie Schnapp-Gourbeillon sugere, em Lions, héros, masques: les représentations de l'animal chez Homère (a partir de Le pur et l'impur de Louis Moulinier), que a lavagem no mar se justificaria no caso de uma mácula (ou impureza: "souillure") grave, pois a água lustral ou a água corrente seriam insuficientes para isso e apenas o mar lavaria tudo (SCHNAPP-GOURBEILLON, 1981, p. 118). Poderíamos, no entanto, acrescentar que, após esta lavagem no mar, um banho com água doce seria necessário para retirar o sal da água do mar. Ver o seguinte comentário de Bryan Hainsworth: "Uma vez que os heróis já se banharam no mar, a razão de ser da banheira deve ser que ela provê um banho quente [...] e água doce para remover o sal do mar" (HAINSWORTH, 1993, p. 209, tradução minha).
} 
contados no presente (como o massacre dos pretendentes) ou enquanto memória (a missão de espionagem de Odisseu-mendigo e o cavalo de madeira em Troia, o ataque surpresa a Proteu por Menelau, ou ainda o cegamento do Ciclope e a saída de sua gruta) na Odisseia, fazendo, de algum modo, do canto X o mais odisseico dos cantos da Ilíada, ainda que inscrito em um modelo alternativo de guerra (o da "emboscada" ou guerrilha) que faz parte da tradição épica homérica como um conjunto e não é exclusividade da Odisseia.

Apenas para lembrar alguns elementos deste modelo de narrativa de "emboscada", poderíamos citar (na esteira do capítulo "The Poetics of Ambush” do livro já citado de C. Dué e M. Ebbott [2010, p. 31-87]): a noite, que torna a distinção visual mais difícil, exigindo uma acuidade auditiva; o armamento ou disfarce (como peles de animal) que não deve brilhar (como o bronze) para não chamar a atenção; armas de tiro à distância mais imprevisíveis como o arco ${ }^{11} \mathrm{o}$ trabalho ou atividade em dupla ou em grupo (potenciando a diversidade da inteligência e da força), mas sempre com a escolha dos melhores; ou ainda (o que é típico da $m \underline{e}$ tis) o aproveitamento rápido das boas ocasiões que se apresentam.

Quanto ao penúltimo elemento citado, o trabalho em dupla, que permitiria uma melhor ou mais ampla "percepção da situação" (nóos), ${ }^{12}$

${ }^{11}$ Coincidentemente também é uma dupla, Trasimedes (filho de Nestor) e Meríones (escudeiro de Idomeneu), que lideram os guardas (e, portanto, também estão acordados) no posto mais avançado do acampamento aqueu, que dará os elmos foscos para Diomedes e Odisseu, sendo que é Meríones quem dará um arco (além de uma aljava e uma espada) para Odisseu (cf. Ilíada X, 260-271), que, no entanto, só o utilizará como uma espécie de chicote para estimular os cavalos (cf. Ilíada X, 513-514). Ora, a figura fingida (por Odisseu-mendigo) do irmão mais novo de Idomeneu na Odisseia lembra muito Meríones por suas características e poderia estar sendo usada como um modo cifrado de sinalizar para Penélope a verdadeira identidade do mendigo. Ver para tanto o artigo de Adele J. Haft, “Odysseus, Idomeneus and Meriones: The Cretan Lies of Odyssey 13-19” (1984, p. 295-298) e também toda a primeira parte, “Odysseus” (e, em especial, o capítulo 4, "The Younger Brother"), do livro Eve of the Festival: Making Myth in Odyssey 19 de Olga Levaniouk (2011, p. 21-189, p. 56-81).

${ }^{12}$ Para uma definição de nóos como uma espécie de "sexto sentido" (a partir das cinco sensações), mas prático e não exatamente intelectual, permitindo em uma dada situação avaliar como se portar e o que é preciso fazer, ver o artigo de Kurt von Fritz "Nóo $\varsigma$ and vocivv in the Homeric Poems" (1943). 
facilitando um bom resultado ou "ganho" (kérdos), tal como o justifica Diomedes (cf. Ilíada X, 224-226) um pouco antes de escolher Odisseu como companheiro por sua "capacidade extraordinária de perceber" (períoide noêesai), responsável pelo provável "retorno" ou sobrevida da "dupla" (ámpho nostésaimen), mesmo em uma situação muito adversa (cf. Ilíada X, 246-247), este elemento, bem marcado formalmente (desde sua aparição: sýn te dý erkhoméno, "e dois indo juntos", Ilíada $\mathrm{X}, 224)$ pelo uso do número dual, reaparece na cena de banho e na do assentar-se (que funciona como transição para a do banquete) também pelo uso do número dual, em um artigo definido (tò), dois particípios médios (loessaméno e aleipsaméno) e um verbo finito (ephizanéten): "E os dois, tendo se banhado e ungido à larga com óleo,/ para o jantar se assentaram [...]" (Ilíada X, 577-578, itálicos meus), no que poderia também ser pensado como uma contraposição mínima (que prenuncia o trabalho coletivo) ao isolamento de Aquiles que, por causa da cólera, se retira do combate e da comunidade guerreira aqueia. É, aliás, na ausência de Aquiles (e em presença de um triunfo temporário de Heitor), sob o signo de uma premente "necessidade" (khreó ou khreió), termo recorrente na preparação desta expedição noturna de espionagem (cf. Ilíada X, $43,85,118,142,172$ ), que os chefes aqueus irão se reunir para, a partir de uma sugestão de Nestor, tentar esta expedição. Coincidentemente, mesmo que o dual não seja usado, a convocação do Conselho dos chefes começa com um trabalho conjunto dos dois irmãos e reis Agamêmnon e Menelau, que estão igualmente preocupados e insones (cf. Ilíada X, 36-71) e vão respectivamente chamar (o primeiro) Nestor e (o segundo) Ájax e Idomeneu. ${ }^{13}$

\footnotetext{
${ }^{13}$ Ver para a oposição entre o estilo de ação individualista (de Aquiles) e o cooperativo (de Agamêmnon e Menelau), além da discussão sobre o tema da "necessidade" nos cantos IX a XI da Ilíada, o artigo (que em boa parte nos inspira aqui) "The Theme of Need in Iliad 9-11" de Robert Rabel (1991). Este artigo permite ver também como o canto X está bem situado entre o fracasso da embaixada de Agamêmnon no canto IX, reforçando a necessidade de Aquiles para o exército aqueu (e a dimensão coletiva do combate), e - depois do ferimento de Agamêmnon, Diomedes, Odisseu e Macáon no canto XI - a intensificação desta necessidade, resultando (no fim do canto XI) na sugestão de Nestor para Pátroclo de que Aquiles o libere para substituí-lo (usando a
} 
Não será, assim, uma surpresa que um dos dois protagonistas aqueus no canto $\mathrm{X}$ da Ilíada seja justamente Odisseu, o herói maior da Odisseia, e que o outro, Diomedes, seja associado a Odisseu em certas histórias também alternativas (ou de "emboscada") do Ciclo Épico Troiano, como o roubo noturno do paládio, a captura de Heleno e de Filoctetes (na Pequena Ilíada) ou a traição e afogamento de Palamedes (na ou nos Cípria). ${ }^{14}$ Ora, deste tipo de história de uma expedição ou "jornada" (quando bem sucedida) faria parte também um "retorno" (nóstos, associável ao nóos, "inteligência prática perceptiva", segundo a sugestão de Douglas Frame em The Myth of Return in Early Greek Epic [1978, p. 1-33]) que, consagrando a salvação e a segurança dos heróis, após todo um risco extremo de morte, poderia ganhar a forma, sinalizando a sobrevida, de um banho e uma refeição que o sucede, como ocorre em muitos episódios de viagem da Odisseia, poema que como um conjunto pode ser pensado como um nóstos ("retorno") da grande expedição guerreira a Troia contada pela Ilíada. ${ }^{15}$

armadura dele e conduzindo os Mirmidões ao combate), o que acabará por levar à morte de Pátroclo e, só a partir dela, ao retorno de Aquiles à comunidade dos guerreiros aqueus. Será em torno de Pátroclo que se articulará o tema da philótes ("amizade"), de algum modo prenunciado também no canto $\mathrm{X}$, como o que irá se opor e levar a um fim a mênnis ("cólera") de Aquiles, que é o tema central do poema. Ver para este tema central e decisivo no poema a monografia de Dale Sinos Achilles, Patroklos, and the Meaning of philos (1980) e o capítulo 5 do livro de Leonard Muellner The Anger of Achilles (1996, p. 133-175).

${ }^{14}$ Para os testemunhos, o resumo de Proclo e os fragmentos da Pequena Ilíada, ver “The Little Iliad" em M. L. West, Greek Epic Fragments (2003, p. 118-143). Para os testemunhos, o resumo de Proclo e os fragmentos da (ou dos) Cípria, ver "Cypria" em West, M. L., Greek Epic Fragments (2003, p. 65-107). Ver também os comentários de Casey Dué e Mary Ebbott sobre as ações desta dupla em "emboscadas" no Ciclo Épico Troiano em Iliad 10 and the Poetics of Ambush (2010, p. 284-286).

${ }^{15}$ Esta, portanto, seria a conexão temática desta cena de banho (e banquete) única na Ilíada e as várias cenas de banho após viagens (e chegadas) na Odisseia, mesmo que neste poema estas cenas de banho sejam também parte de um ritual de hospitalidade. É esta, por sinal, a crítica pertinente que Casey Dué e Mary Ebbott fazem ao artigo ("The Poetics of Bath in the Iliad") já citado de Jonas Grethlein: "[...] na sua separação da Ilíada e Odisseia, ele parece desconsiderar que a chegada após uma viagem, além de ser simplesmente uma ocasião para hospitalidade, frequentemente inclui na Odisseia uma 
Ainda que o encaixe do canto X no conjunto da Ilíada possa parecer problemático (tanto do ponto de vista temporal, pois já há todo o episódio também noturno da embaixada a Aquiles contado no canto IX, quanto do da sua função algo supérflua na intriga central da "cólera" de Aquiles), levando comentadores ou editores (como recentemente Martin L. West) ${ }^{16}$ a considerá-lo um acréscimo ou interpolação; se pensarmos que ele está composto, segundo a lógica alternativa da "emboscada", com elementos ou microunidades narrativas (as chamadas cenas típicas homéricas, como o banho e a refeição, por exemplo) que se associariam tematicamente - a partir de um estoque comum tradicional - em um modo de composição oral mais fluido (tal como foi proposto por Albert Lord em The Singer of Tales [1960, p. 68-98]), talvez nós não precisássemos nos perguntar, a partir do critério todo poderoso e algo anacrônico da verossimilhança, como uma algo pesada e luxuosa "banheira" (asáminthos) teria sido transportada em naus para fazer parte dos utensílios de um mero acampamento. ${ }^{17} \mathrm{Ou}$ - outra pergunta análoga

medida semelhante de segurança após um perigo como a que ele vê no retorno de um guerreiro do campo de batalha na Ilíada" (DUÉ; EBBOTT, 2010, p. 380, tradução minha). 16 "A Ilíada da Teubner (1998-2000) de Martin West [...] coloca entre colchetes o canto 10 da Ilíada na sua totalidade como uma interpolação que não faz parte do poema" (DUÉ; EBBOTT, 2010, p. 24, tradução minha). Ver os colchetes indicadores do acréscimo (ou interpolação) na edição de Martin L. West Homeri Ilias, volumen prius: rhapsodiae I-XII (1998, p. 286-312).

${ }^{17}$ O comentário de Walter Leaf (do comecinho do século XX) é, neste sentido, exemplar: "As 'banheiras polidas', apesar de bastante comuns nos palácios da Odisseia, não são encontradas em outro lugar na Ilíada, e parecem antes fora de lugar no meio do mobiliário de um acampamento. O verso inteiro é, de fato, simplesmente copiado da Odisseia" (LEAF, 1955, p. 496, tradução minha). Semelhantemente, apesar do reconhecimento do modo narrativo de composição por cenas típicas (ou "temas"), Bryan Hainsworth suspeita da verossimilhança de tais "amenidades" palacianas típicas da Odisseia nas tendas ou barracas de um acampamento (ver também o começo de seu comentário na próxima nota): "Há mais do que uma simples suspeita de 'superposição temática' a partir deste ponto até o fim do canto [...], na medida em que os heróis se deliciam com as amenidades de um palácio odisseico que estão totalmente fora de lugar em suas klisíai ao longo da praia" (HAINSWORTH, 1993, p. 209, tradução minha). Mas, mesmo do ponto de vista da mera verossimilhança (e ainda que nenhuma menção a isso seja feita em todo o poema), seria possível imaginar que estas banheiras 
feita por muitos - como Diomedes teria feito duas refeições e Odisseu até mesmo três em apenas uma noite ${ }^{18}$ (a do Conselho dos Anciãos no começo do canto IX por Diomedes e Odisseu, a de recepção de Odisseu por Aquiles em sua barraca um pouco depois neste mesmo canto IX, ${ }^{19} \mathrm{e}$ enfim esta de chegada ao acampamento aqueu por Diomedes e Odisseu, no fim do canto $\mathrm{X}){ }^{20}$ pois, em cada um destes casos, a refeição, enquanto instância de sociabilidade ou consagração de uma expedição noturna bem sucedida, tem uma função que extrapola o seu mero caráter de reposição alimentar (mesmo que usássemos o recurso de um escoliasta, o "Arn/A", de considerar esta última refeição não como uma ceia tardia, mas já como um "café da manhã", áriston, antecipado). ${ }^{21}$

tivessem sido trazidas dos saques de cidades circunvizinhas a Troia, como observou com engenhosidade Rafael Guimarães Tavares Silva (a quem aproveito para agradecer aqui) na discussão após a apresentação de uma versão preliminar deste texto no "Seminário do NEAM (da FALE-UFMG)" no dia 24/05/2018.

18 "A familiaridade impediu o poeta de considerar que as banheiras (habitualmente artefatos de cerâmica pesados, arqueologicamente) eram uma amenidade improvável para um exército em campanha; e, semelhantemente, que o deîpnon era a segunda refeição de Diomedes e a terceira de Odisseu esta noite" (HAINSWORTH, 1993, p. 209, tradução minha). Ver também a nota para deípnoi de Walter Leaf: "[...] como a Ilíada hoje está composta, este é o terceiro deîpnon que Odisseu desfrutou durante esta noite longa e cheia de eventos" (LEAF, 1955, p. 497, tradução minha).

${ }^{19}$ De algum modo, Odisseu parece reconhecer que, do ponto de vista estritamente fisiológico da reposição periódica de energia através da alimentação, a refeição oferecida por Aquiles, quando os enviados de Agamêmnon (Odisseu, Ájax e Fênix) chegam à barraca dele (Aquiles), não é necessária, após um primeiro banquete oferecido há pouco por Agamêmnon (e sendo tão crítica a situação dos aqueus, com a vitória e a proximidade dos troianos): "Salve, Aquiles; de um banquete igual não necessitados/ estávamos na barraca do Atrida Agamêmnon/ nem também aqui agora: pois com muita comida satisfatória/ vos banqueteais; mas não nos preocupam as ações de um desejável banquete,/ mas a um demasiado grande sofrimento, ó criado por Zeus, observando/ nós tememos [...]" (Ilíada IX, 225-230).

${ }^{20}$ Mas neste caso, com toda a atividade física suposta em uma missão noturna arriscada como esta e bem explicitada pelo "muito suor" que ela causou na dupla de guerreiros aqueus (que também justifica este único duplo banho na Ilíada), a reposição de energia por uma nova refeição estaria justificada, segundo o critério algo anacrônico da verossimilhança.

${ }^{21}$ Cf. Scholia graeca in Homeri Iliadem, v. 3 (ERBSE, 1974, p. 116). 
É, de qualquer modo, evidente, no caso desta última refeição (a do fim do canto $\mathrm{X}$ ), a omissão não só de sua preparação, mas também daquilo que os dois teriam comido, ${ }^{22}$ sendo que, quanto a ela, poderíamos também pensar, ainda que a dupla não esteja aí acompanhada por ninguém mais, em uma instância mínima de sociabilidade (simbolicamente também condizente com a oposição ao isolamento de Aquiles), uma vez que em Homero é praticamente inexistente a descrição de uma refeição totalmente solitária.

\section{Referências}

\section{Textos antigos}

ERBSE, H. (Ed.). Scholia graeca in Homeri Iliadem. Berlin: Walter de Gruyter, 1974. v. 3.

HOMER. Homeri Ilias. Recognovit Helmut Van Thiel. Hildesheim: Olms, 1996.

HOMER. Homeri Ilias: volume prius - rhapsodiae I-XII. Edited by M. L. West. Leipzig: Teubner, 1998.

HOMER. Homeri Ilias: volumen alterum -rhapsodiae XIII-XXIV. Edited by M. L. West. Leipzig: Teubner, 2000.

HOMER. Homeri Opera: Ilias tomi I-II. 7. ed. Edited by Thomas W. Allen and David B. Monro. Oxford: Oxford University Press, 1989 [1902].

\footnotetext{
${ }^{22}$ Por outro lado, assim como a menção de uma oferenda sacrificial a Atena parece antecipar (numa espécie de composição em anel) a libação com que a cena conjunta de banho e refeição termina, assim também esta refeição apenas indicada é, de algum modo, antecipada pela suposta refeição dos cavalos de Reso capturados pelos dois aqueus, pois estes cavalos são amarrados com correias à manjedoura onde os cavalos de Diomedes estavam postados, "comendo o trigo agradável-como-mel" (cf. Ilíada X, 567-569). Isso indica bem, no interior da Ilíada, uma conexão com os cavalos (extraordinários) de Eneias, capturados por Diomedes e Estênelo no canto V, mas também faz lembrar, na Odisseia, a antecipação do grande banquete de recepção de Telêmaco e Pisístrato por Menelau, pelo modo como os escudeiros deste último desatrelam e preparam a refeição dos dois cavalos que puxavam o carro que transportava Telêmaco e Pisístrato de Pilos até Esparta (cf. Odisseia IV, 39-41).
} 
HOMERO. Ilíada. Tradução de Carlos Alberto Nunes. São Paulo: Hedra, 2011 [Atena, 1943].

HOMERO. Ilíada. Tradução de Frederico Lourenço. Lisboa: Cotovia, 2005.

WEST, M. L. (Ed.). Greek Epic Fragments: From the Seventh to the Fifth Centuries BC. Edited and translated by Martin L. West. Cambridge Mass.: Harvard University Press, 2003.

\section{Textos modernos}

AREND, W. Bad. In: Weidmann, 1933. cap. 10, p. 124-126.

. Die typischen Scenen bei Homer. Berlin:

DUÉ, C.; EBBOTT, M. Iliad 10 and the Poetics of Ambush. Cambridge Mass.: Harvard University Press, 2010.

EDWARDS, M. W. Homer and the Oral Tradition: The Type-Scene. Oral Tradition, Columbia, v. 7, n. 2, p. 284-330, 1992.

FOLEY, J. M. Thematic Structure in the Odyssey. In: Traditional Oral Epic: The Odyssey, Beowulf, and the Serbo-Croatian Return Song. Berkeley: University of California Press, 1990. p. 240-271.

FRAME, D. The Myth of Return in Early Greek Epic. New Haven: Yale University Press, 1978.

GINOUVÈS, R. Balaneutiké: Recherches sur le bain dans l'Antiquité grecque. Paris: Éditions E. de Boccard, 1962.

GRETHLEIN, J. The Poetics of Bath in the Iliad. Harvard Studies in Classical Philology, Cambridge Mass., v. 103, p. 25-49, 2007.

HAFT, A. J. Odysseus, Idomeneus and Meriones: The Cretan Lies of Odyssey 13-19. The Classical Journal, Monmouth, v. 79, n. 4, p. 289306, 1984.

HAINSWORTH, B. Book Ten. In: . The Iliad: A Commentary. Volume III: books 9-12. Cambridge: Cambridge University Press, 1993. p. 151-210. 
HOMER. The Iliad of Homer: vol. I (Books I-XII). Edited with general and grammatical introductions, notes, and appendices by W. Leaf. London: Macmillan \& Co. Ltd., 1955 [1902].

LEVANIOUK, O. Odysseus. In: . Eve of the Festival: Making Myth in Odyssey 19. Cambridge Mass.: Harvard University Press, 2011. p. 21-189.

LORD, A. B. Composition by Theme in Homer and Southslavic Epos. Transactions of the American Philological Association, Baltimore, v. 82, p. 71-80, 1951.

LORD, A. B. The Theme. In: . The Singer of Tales. Cambridge, Mass.: Harvard University Press, 2000 [1960]. p. 68-98.

MUELLNER, L. The Anger of Achilles: Mênis in Greek Epic. Ithaca: Cornell University Press, 1996.

NAGY, G. Introduction. In: The Best of the Achaeans. Cambridge Mass.: Harvard: University Press, 1979. p. 1-7.

RABEL, R., The Theme of Need in Iliad 9-11. Phoenix, Toronto, v. 45, n. 4, p. 283-295, 1991.

REECE, S. The Homeric A $\sigma \alpha{ }^{\mu} \mu 1 v \theta o$ s: Stirring the Waters of the Mycenaean Bath. Mnemosyne, Amsterdan, v. 55, p. 703-707, 2002.

SCHNAPP-GOURBEILLON, A. Lions, héros, masques: les représentations de l'animal chez Homère. Paris: François Maspero, 1981. VERNANT, J.-P. Le pur et l'impur. In:___. Mythe et société en Grèce ancienne. Paris: François Maspero, 1974. p. 121-140.

VON FRITZ, K. Nóos and vocĩv in the Homeric Poems. Classical Philology, Chicago, v. 38, n. 2, p. 79-93, 1943.

WEIL, S. A Ilíada ou o poema da força. In: . A condição operária e outros estudos sobre a opressão. 2. ed. Organização de Ecléa Bosi, tradução de Alfredo Bosi. Rio de Janeiro: Paz e Terra, 1996. p. 379-407.

Recebido em: 20 de setembro de 2018. Aprovado em: 28 de novembro de 2018. 